\title{
Entre fluxos, pessoas e territórios: delineando a inserção do terapeuta ocupacional no Sistema Único de Assistência Social
}

\author{
Patrícia Leme de Oliveira Borba ${ }^{a}$, Samira Lima da Costa ${ }^{\mathrm{b}}$, Ana Carolina Costa Savanic, \\ Camila Cardoso Anastáciod, Natacha Harumi Ota ${ }^{e}$
}

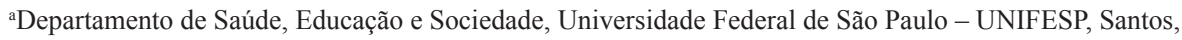
SP, Brasil.

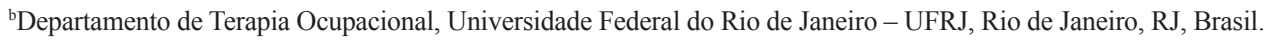

${ }^{\mathrm{c} A s s o c i a c ̧ a o ~ P a u l i s t a ~ p a r a ~ o ~ D e s e n v o l v i m e n t o ~ d a ~ M e d i c i n a, ~ S a ̃ o ~ P a u l o, ~ S P, ~ B r a s i l . ~}$

${ }^{d}$ Congregação das Irmãs Hospitaleiras, São Paulo, SP, Brasil.

${ }^{e}$ Hospital Municipal de Mogi das Cruzes, Mogi das Cruzes, SP, Brasil.

\begin{abstract}
Resumo: Este trabalho apresenta a proposta realizada entre os anos de 2011 a 2014 no módulo do estágio profissionalizante em Terapia Ocupacional no campo social do curso de Terapia Ocupacional da Universidade Federal de São Paulo (UNIFESP). Nesse cenário, alinhando-nos com a Política Nacional de Assistência Social (PNAS) e com os pressupostos teórico/práticos da Terapia Ocupacional Social, desenhamos ações territoriais - individuais e coletivas - com o intuito de fortalecer, criar e constituir as redes relacionais de famílias e de pessoas daquela região referenciadas pela rede de proteção social - básica e/ou especial de média e alta complexidade -, tendo como ponto de partida a demanda apresentada a partir de um processo da criação de laços de confiança entre terapeuta ocupacional e sujeito/grupo. Nesse sentido, descreve-se e reflete-se sobre cinco experiências: o apoio às reuniões de território a partir de um Centro de Referência da Assistência Social (CRAS), a composição de trabalho de um CRAS com um Serviço de Convivênci a para Jovens e três acompanhamentos singulares e territoriais. Esse desenho de estágio tem explicitado o desafio de formar o aluno com base na demanda do outro e fundamentado na perspectiva do território e da intersetorialidade enquanto campo e prática de potencial resolutividade.
\end{abstract}

Palavras-chave: Terapia Ocupacional Social, Território, Proteção Social.

\section{Between flows, people and territories: outlining the insert of occupational therapist in the Brazilian Social Assistence System}

\begin{abstract}
This essay presents the purpose which took place from 2011 through 2014, by the Professional Trainning of Social Occupational Therapy of the Occupational Therapy Course at Federal University of São Paulo in the city of Santos, SP. Aligned to the National Politics of Social Assistance as well as Social Occupational Therapy practical/theoretical assumptions, was designed territorial actions - individual and collective - to strengthen, to create and to form family and people relational networks, and people from Santos served by a social protection network - basic and/or special of medium and high complexity -, based on the demand presented through a process of creating bonds of trust between occupational therapist and subject/group. In this sense, it is described and reflected on five experiences: the support to the Regional Meetings from a Social Assistance Reference Center (CRAS), the work composition of a CRAS with a Social Service for young people and three individual and territorial support. This experience reveals the challenge of educating the student based on the other one need, as well as based on its territory and intersectoriality as a practice with efficiency.
\end{abstract}

Keywords: Social Occupational Therapy, Territory, Social Protection.

Autor para correspondência: Patrícia Leme de Oliveira Borba, Departamento de Saúde, Educação e Sociedade, Universidade Federal de São Paulo, Rua Silva Jardim, 136, CEP 11015-020, Santos, SP, Brasil, e-mail: patricialemeborba@hotmail.com

Recebido em Nov. 15, 2015; $1^{\text {a }}$ Revisão em Mar. 19, 2016; 2 ${ }^{\text {a }}$ Revisão em Maio 19, 2016; Aceito em Jul. 6, 2016. 


\section{Introdução}

Este trabalho apresenta a experiência realizada entre os anos de 2011 e 2014, durante o estágio profissionalizante em Terapia Ocupacional Social do curso de Terapia Ocupacional da Universidade Federal de Sáo Paulo (UNIFESP), do campus Baixada Santista. Ao longo de seis semestres letivos, esse campo de estágio contou com a supervisão de dois docentes e recebeu 24 estudantes do curso de Terapia Ocupacional.

Com vistas a acompanhar as tendências contemporâneas da Terapia Ocupacional Social, organizamos o estágio voltado para a Política Nacional de Assistência Social (PNAS) com base em uma proposta territorial, com foco nas pessoas, famílias e grupos que apresentam fragilidades ou rompimento em suas redes de suporte sociais, a partir da utilização dos recursos existentes no território.

\section{A PNAS e a Participação da Terapia Ocupacional}

A PNAS, desde seu desenho embrionário na Constituição de 1988 até os dias de hoje, passou por marcos históricos que contribuíram para consolidar a assistência social como direito social, atuando na garantia de direitos e no combate intransigente das violaçốes e violências de toda ordem. $\mathrm{O}$ texto constitucional sobre assistência social (inscrito no capítulo sobre seguridade social), aprovado em 1988, teve sua primeira regulamentação em 1993 por meio da publicação da Lei Orgânica da Assistência Social (LOAS). Foram necessários mais de 10 anos de luta após a criação da LOAS para que o país tivesse finalmente publicada a PNAS (BRASIL, 2004), a Norma Operacional Básica (NOB), que ordena seus serviços em sistema - o Sistema Único de Assistência Social (SUAS) (BRASIL, 2005) -, e a NOB de Recursos Humanos, que define a composição de suas equipes (BRASIL, 2007).

Essas publicaçôes marcaram um grande avanço para o Brasil, que vinha até entâo construindo vasto histórico filantrópico e assistencialista. Entretanto, as publicações da PNAS e da NOB-SUAS se caracterizaram como marcos de uma luta ainda em processo. Embora a política previsse a cobertura da ampla diversidade e complexidade do país, a composição das equipes ficou reduzida a apenas duas categorias de profissionais. Só em 2011, a NOB-RH foi revista, ampliando para oito as categorias de profissionais que podiam compor as equipes de referência dos serviços da assistência social. Entretanto, a chamada equipe mínima segue concentrada nas duas primeiras: psicólogos e assistentes sociais.

Embora na NOB-RH, inicialmente, as equipes de referência de trabalhadores do SUAS fossem restritas a psicólogos e assistentes sociais, historicamente a assistência social no Brasil tem sido desenvolvida e discutida por várias outras categorias profissionais. O campo da assistência social se caracterizou fortemente no Brasil pela assistência às demandas de diferentes grupos populacionais marcados pela vulnerabilidade social, por meio de diversos recursos, serviços, profissionais e estratégias, necessárias diante da diversidade da população. Sendo assim, a restrição da equipe a duas profissóes representou um retrocesso com relaçáo ao que já vinha ocorrendo de fato, ainda que a regulamentação da política e de sua rede de serviços tenham se constituído em considerável avanço.

Considerando que uma equipe reduzida a duas profissóes seria insuficiente para acolher a diversidade e enfrentar a complexidade das problemáticas que se apresentavam nos serviços da assistência social, os trabalhadores dessa política, organizados em forma de fórum permanente, passaram a discutir a necessidade de ampliação e de diversificação da equipe.

E foi nessa esteira de debates e de reivindicaçôes de ampliação da equipe enquanto direito do usuário que, em 2011, foi publicada a revisão da NOB-RH para o SUAS por meio da Resoluçáo no 17/2011 do Conselho Nacional da Assistência Social (CNAS) ${ }^{1}$, na qual outras seis profissóes - além das duas já constantes desde o início - passaram a ser reconhecidas como integrantes das equipes de referência dos serviços que compóem a rede socioassistencial do SUAS, entre as quais a Terapia Ocupacional. Foi, portanto, em 2011 que a categoria profissional Terapia Ocupacional passou a compor a Resolução de Recursos Humanos do SUAS (NOB-RH) como um dos profissionais previstos para a composição das equipes dos serviços indicados pelo sistema, bem como a realizar funçóes de gestão.

Nesse mesmo ano, estabeleceram-se grupos de debate entre os profissionais envolvidos com a área da assistência social, com base na Resoluçáo CNAS no 172/2007 (BRASIL, 2007, p. 1), que recomendava a

[...] instituição de Mesas de Negociações com composição paritária entre gestores, prestadores de serviço e trabalhadores da área de assistência do setor público e do setor privado, como forma de conduzir a gestão do trabalho no âmbito do SUAS. 
Para que se convocasse as categorias profissionais que representavam os trabalhadores do SUAS, fazia-se necessário definir claramente quais seriam elas. Desse modo, terapeutas ocupacionais de todo o Brasil atuantes no âmbito da assistência social - tanto os acadêmicos, que trabalham na formação de profissionais para atuação nessa política, quanto os que atuam em seus serviços, diretamente -, participaram de debates acerca das contribuiçóes da profissão na gestáo e na execução dessa política. Em torno dessa discussão, constituíram-se parâmetros referenciais para a atuação profissional no SUAS, grupos de trabalho sobre Terapia Ocupacional no SUAS, mesas de debate e eixos temáticos em encontros da profissão. Essa foi a primeira etapa de uma luta que segue ao mesmo tempo preocupada com a formação do profissional, preparado para atuar no âmbito dessa política, e investida na garantia dos direitos dos usuários a serviços e profissionais adequados às suas diferentes demandas e perfis. Cabe destacar que o atual modelo de gestáo, fortemente ancorado na perspectiva do estado mínimo, deixa de fora todas as profissōes que não estejam arroladas como estritamente necessárias, ou seja: apenas as profissôes componentes da equipe mínima têm, via de regra, seus cargos e funçôes regulamentados em todo o território nacional. As demais profissóes seguem à margem da política, uma vez que, nesse registro de gestão, o documento que revisa a NOB-RH se torna tấo ou muito somente uma orientação. A efetivação da contratação dos demais profissionais - para além das equipes mínimas, que continuam compostas pelas mesmas duas profissóes iniciais - exige ainda muitas negociaçôes.

Além das já referidas negociaçôes, há também a necessidade de continuidade da produção de subsídios teóricos e práticos que ofereçam sustentaçáo para a ação da Terapia Ocupacional alinhada ao que preconiza a PNAS. Para tanto, é preciso destacar que não há espaço, nessa política, para perspectivas profissionais que se ancorem nos pressupostos $\mathrm{da}$ clínica e da saúde, sob o risco de ter sua atuação desconsiderada. Em outras palavras, embora haja um histórico de lutas e de constructos teóricos da Terapia Ocupacional que garantiram sua imersão e inserção na Política Nacional de Saúde, o processo de sua inclusão na PNAS demanda outros referenciais.

Assim, torna-se necessário avançar na oferta de subsídios para os novos atores, terapeutas ocupacionais, que integram e seguirão integrando cada vez mais essa rede de proteção, bem como analisar as experiências práticas da atuação profissional no interior dessa política, em diálogo com as outras profissóes que também compóem esse campo.

\section{A Experiência do Campo de Estágio}

Com base na história de inserção profissional e na reflexão acerca da relevância da produção de conhecimento sobre a Terapia Ocupacional na assistência social, o presente relato foi elaborado tomando como base a experiência de estágio profissional de Terapia Ocupacional na rede SUAS.

O campo descrito foi realizado no território Centro da cidade de Santos, a partir de um Centro de Referência da Assistência Social (CRAS). O campo de estágio foi vivenciado por estudantes de $7^{\circ}$ e $8^{\circ}$ períodos, ao longo de seis semestres letivos. Para tanto, contou-se também com a presença constante de duas docentes supervisoras do curso de Terapia Ocupacional da UNIFESP.

No desenho curricular do estágio, o pilar de toda ação é pautado na perspectiva territorial. Compreende-se que a concepção de território está para além de uma delimitação geográfica de uma dada região, ocupada por uma comunidade. Incluímos nesse conceito, necessariamente, a constituição histórica local e as relações socioeconômicas e culturais ali desenvolvidas, nas quais se observam diferentes formas de vida e de realização de trocas sociais (OLIVER; BARROS, 1999).

A perspectiva da ação territorial para a Terapia Ocupacional parte das primeiras experiências mobilizadas pelos técnicos da reforma psiquiátrica italiana. Permaneceu como estratégia de ação e de construção das políticas públicas sociais, com destaque para os setores da saúde e da assistência social, uma vez que tanto o Sistema Único de Saúde (SUS) como o SUAS (preconizam o desenvolvimento de ações territoriais (LOPES et al., 2013). Nessas políticas, os serviços precisam, necessariamente, estar próximos do seu público - próximos fisicamente - no sentido geográfico - e próximos de seu contexto - no sentido de se levar em consideração os aspectos sociais, históricos, econômicos, políticos e culturais de um determinado lugar. Visa, assim, compreender e compartilhar as formas como as relaçóes naquele espaço se processam, como as pessoas vivem, pensam, sonham, trabalham, organizam seu cotidiano, por onde circulam, como acessam os bens públicos, quais são suas atribuiçóes de valores, como as redes se ativam e se redirecionam, como as potências se manifestam e se calam (BARROS et al., 2007). 


\subsection{Santos, cidade-polo da Região Metropolitana da Baixada Santista}

Segundo dados do Instituto Brasileiro de Geografia e Estatística - IBGE (INSTITUTO..., 2011), a cidade de Santos possui $280.674 \mathrm{~km}^{2}$ de área territorial, contando com 419.400 mil habitantes, com estimativa de 433.565 mil habitantes para o ano de 2015. É importante destacar que a distribuição das pessoas na área geográfica é bastante desigual, existindo uma grande concentração na parte insular e um vazio na área continental, cuja maior parte é composta por uma unidade de conservação ambiental. Outra questão bastante singular dessa cidade foi o deslocamento do núcleo de atividades comerciais de caráter local do Centro para a Orla, tendo permanecido na região central apenas o comércio de grande porte ligado, principalmente, a atividades alfandegárias e portuárias, ou seja, grande parte das trocas comerciais náo é mais realizada no Centro da cidade. Isso provocou um contínuo processo de precarização e pauperização da regiáo central, onde há hoje muitas casas abandonadas - em sua maioria, transformadas em moradias irregulares e/ou cortiços -, uma quantidade expressiva de pessoas em situação de rua, bares e danceterias que compóem o eixo boêmio de baixo custo da cidade e uma importante rede de tráfico de drogas e de prostituiçáo. No entanto, coexiste um centro comercial e bancário significativo, a alfândega e a zona portuária, locais de grande circulação de valores da cidade e do país, um tráfego intenso de transportes pesados devido ao porto - navios, trens e caminhóes de carga -, além de prédios e de monumentos que compóem o eixo turístico da cidade, diretamente ligados à sua história.

De acordo com a divisão em regiốes pela Secretaria Municipal de Assistência Social, a região Centro foi dividida em quatro territórios, a saber: Orla, Zona Intermediária, Centro Histórico e Área Continental, o que resulta em uma extensa área geográfica e multicultural com cobertura de um mesmo equipamento, o CRAS-Centro. Entre 2014 e 2015, o CRAS-Centro passou por um processo de revisão dos territórios de cobertura, com a criação de um novo CRAS, de forma que os quatro territórios foram redistribuídos entre os dois serviços: CRAS-Centro (territórios Centro Histórico e Área Continental) e CRAS-ZOI (territórios Zonas Orla e Intermediária).

Foi no cenário que agrupava quatro territórios que as açóes aqui descritas foram inicialmente desenvolvidas, passando, posteriormente, a apoiar o processo de reorganizaçáo dos serviços e das referências por território. Nesse processo, buscou-se o alinhamento com os pressupostos teórico-práticos da Terapia Ocupacional Social (BARROS; GHIRARDI; LOPES, 1999, 2002) e com a PNAS (BRASIL, 2004).

Todas as açôes do estágio em Terapia Ocupacional no campo social em serviços da assistência social com base territorial, sejam elas individuais ou coletivas, tinham o intuito de fortalecer, criar e constituir as redes relacionais de famílias e pessoas daquela região referenciadas pela rede de proteção social - básica e/ou especial de média e alta complexidade. $O$ estágio teve base no CRAS, mas não se restringiu a ele. Nesse sentido, os estagiários circulavam pelo bairro e acolhiam demandas vindas de outras portas de entrada, como escolas, organizaçóes não governamentais, serviços da assistência social de outros níveis de proteção, conselhos municipais etc. $\mathrm{O}$ estágio adotou como ponto de partida a demanda apresentada a partir de um processo da criação de laços de confiança entre terapeuta ocupacional e sujeito/grupo. A base de ação e de reflexão é aquilo que existe e se produz nos territórios, em suas muitas formas de compreensão. Parte-se dos recursos do próprio território de ação, podendo ser este o território geográfico das famílias atendidas e dos serviços localizados, mas também considerando outros, incluindo aí os territórios usados da cidade, para além das fronteiras geográficas, e os territórios existenciais, nos quais se produzem modos do saber afirmar-se e existir, ou seja, territórios do saber comunitário, em encontro com os do saber da terapia ocupacional, que se constrói em direção ao outro, por meio de diálogos, invenção de atividades, fazeres conjuntos e articulaçáo de rede de contatos (interserviços).

Assim, a atuação do terapeuta ocupacional nessa perspectiva implicou em nos colocarmos atentos aos modos como a rede de proteçáo social se configurou e, a partir da relação com os sujeitos, individuais e coletivos, aos quais se direcionavam as açóes, acolher e lidar com as demandas/necessidades trazidas por eles, transformando tais demandas em ações propositivas, referenciando-as ao serviço, mas também investindo em redes de suporte para além dos serviços. Daí utilizarmos o acúmulo histórico de nossa profissão sobre a atividade humana para a invenção das açôes cotidianas, estando atentos a como cada pessoa acessava seus direitos, por onde circulava, com quem se apoiava. Nossa compreensão sobre a cotidianidade da vida instalada em cada território nos oferece ferramentas para pensar e agir para além dos muros dos serviços, em direção à proteção social. 
É preciso observar, compreender e atuar diretamente na realidade vivida localmente, mas é igualmente necessário ampliar a compreensão para o contexto macroestrutural. É preciso compreender como o capitalismo, o Estado e as políticas públicas sociais se organizam e se dinamizam. Nesse sentido, tem sido fundamental o apoio nos conceitos de inserçáo social definidos por Castel (1994), que nos auxiliam na compreensão da vulnerabilidade social como condição dinâmica e processual. Tal condiçáo nos permite vislumbrar e apostar nas possibilidades de transformação, entendendo que transcender essa situaçáo implica tecer as redes de suporte, seja pelo eixo do trabalho, seja pelo eixo das relaçôes sociais - entre as pessoas e entre pessoas e serviços.

Sendo assim, as açôes previstas foram criadas a partir da vinculação com os profissionais de diferentes serviços com os quais nos relacionamos.

\subsection{Nos fluxos: alguns exemplos de ações}

A maior parte das demandas acolhidas por nossa equipe de trabalho era advinda da própria equipe do CRAS-Centro, embora não limitada a esse equipamento, para sermos coerentes com a proposição territorial do estágio. Nesse sentido, em menos de um semestre já estávamos construindo e sendo reconhecidos por acolher demandas da rede de serviços instalados naquela microrregiáo. Passamos a ser considerados como um importante apoio e parceria, principalmente, de um serviço de acolhimento para famílias e pessoas em situaçáo de rua, de uma escola municipal, de um centro da juventude, de uma creche e de uma organizaçáo náo governamental para crianças e adolescentes no contraturno escolar, além da própria equipe do CRAS, que nos reconhecia como equipe com destacado trabalho, principalmente em situaçóes em que pessoas e famílias tinham baixa adesão ao serviço e em situaçóes complexas que envolviam vários serviços do território.

As açóes se caracterizaram pelo acolhimento de famílias de forma singular, tanto marcadas pelo acompanhamento institucional quanto territorial. Assim, algumas dessas açôes ocorreram no interior dos serviços citados. Outras ocorreram no território cotidiano do usuário: ruas, praças, calçadas, comércios, residência. A seguir, abordaremos três exemplos de práticas que foram desenvolvidas nesse período, a saber: apoio às reunióes de território a partir do CRAS; composição de trabalho entre o CRAS e a Seção de Acolhimento e Abrigo Provisório de Adultos, Idosos e Famílias em Situação de Rua; composição de trabalho CRAS e Serviço de Convivência para Jovens.

\subsection{Apoio às reuniões de território a partir de um CRAS}

O CRAS é responsável pela articulação da rede de serviços de proteçáo básica local, devendo organizar reunióes periódicas com as instituições que compóem a rede a fim de instituir a rotina de atendimento e de acolhimento dos usuários, organizar os encaminhamentos, fluxos de informaçóes, procedimentos, estratégias de resposta às demandas, e traçar estratégias de fortalecimento das potencialidades do território (JUNQUEIRA, 2000). Na cidade de Santos, esses encontros mensais foram instituídos com o nome de reunióes de território e são constituídos por diferentes atores sociais - profissionais, lideranças comunitárias e usuários - com o objetivo de discutir e de analisar conjuntamente as demandas de cada território e promover açôes integradas que possam superar de maneira articulada os problemas sociais (TATAGIBA, 2005).

Essas reuniōes têm por objetivo promover a articulação de redes. Estas podem ser entendidas como uma linguagem de vínculos, das relaçóes sociais entre organizaçóes que interagem, mediadas por atores sociais que buscam entender de maneira compartilhada uma determinada realidade social. São formas de agir que privilegiam os sujeitos, os quais, de maneira interativa, apropriam-se do conhecimento dos problemas sociais e de sua solução. Sendo assim, esses espaços têm como objetivo integrar os participantes no debate e na resoluçáo dos problemas sociais elencados, bem como na proposição de encaminhamentos (TATAGIBA, 2005).

Nossa experiência se deu na condição de apoiadoras (assessoramento) dessas reunióes de território no CRAS-Centro. O apoio ofertado se fez tanto na concepção da reunião (planejamento operacional e análise conceitual) como em sua execução (condução de algumas atividades, cooperação na coordenaçáo, oferta de modelo de mediação participativa, prontidão de materiais e recursos para as atividades previstas), buscando garantir o fortalecimento do espaço público e da ação coletiva com base democrática.

A participação nesses espaços era majoritariamente de técnicos representantes de serviços que respondiam a diferentes setores das políticas sociais e de fóruns promotores de garantia de direitos, como serviços da rede pública de assistência em diversas áreas, conselhos e entidades do terceiro setor, vinculadas a políticas públicas. Assim, há uma pluralidade de 
percepçóes e compreensóes acerca das necessidades e demandas do território no qual se está inserido.

Esse processo permitiu que a Terapia Ocupacional fosse reconhecida por sua capacidade/habilidade na proposição das metodologias participativas que colaboravam para dinamizar o próprio processo da reunião, lançando mão de recursos lúdicos, dinâmicos e expressivos. Além da criação desses recursos, contribuímos também com: o mapeamento e convite ativo dos serviços que não estavam representados, para que eles passassem a integrar as reuniōes; a criação de guias de informaçôes virtuais sobre os serviços da região; a criação de consensos em torno das temáticas que precisariam ser discutidas pelos técnicos, de forma a favorecer uma maior compreensão acerca do tema elencado.

O grupo de pessoas implicado na condução dessa ação tinha apostado nas tessituras de relaçôes entre os próprios profissionais que integravam ativamente esse grupo. Para tanto, criou-se espaço dentro da reunião para que os profissionais pudessem dialogar entre si. Por isso, tão essencial quanto realizar a reunião formal, era cuidar dos espaços não formais (como o acolhimento inicial dos participantes da reuniáo e a hora do café), bem como garantir apresentação dos seus respectivos serviços, de tal forma que se tornassem mais conhecidos para o grupo os recursos existentes no território e os mecanismos para acessá-los.

Além da apresentação mais formalizada do serviço no interior da reunião, produzimos, a partir dos recursos audiovisuais, pequenos documentários para que os técnicos pudessem apresentar sua realidade cotidiana e expressar suas percepçôes sobre o território. E, por último, constituímos um mapa virtual para facilitar a localização dos serviços e o que eles ofereciam.

A participação nesse processo se tornou uma experiência ímpar na medida em que aglutinou profissionais de diferentes serviços e setores que compunham o campo social - educação, saúde, assistência social, segurança pública, conselhos municipais e tutelares -, fazendo com que se tivesse a compreensão de como se articulavam políticas e açôes coletivas, como no campo social, que pode ser de natureza intersetorial e interdisciplinar. Por fim, o processo contribuiu também para identificar a necessidade de se formar profissionais que consigam mediar reunióes entre os setores e efetivamente corresponsabilizar-se pelas açôes.

Tal prática buscou fomentar o trabalho de articulaçáo de redes intersetoriais, com a reunião de território sendo um lócus privilegiado para esse acontecimento. Esses encontros são permanentes e, por essa condição, precisam ser revitalizados sempre, para não se tornarem algo enfadonho no cotidiano de trabalho dos técnicos sociais, mas, de fato, constituam-se em espaço propositivo, com força política e com condiçóes de avançar em direçâo às garantias e proteçôes sociais dos sujeitos que habitam os territórios.

Composição de trabalho CRAS e serviço de acolhimento de indivíduos e famílias em situação de rua - SEACOLHE-AIF

Mediante demanda apresentada pela Secretaria Municipal de Assistência Social e por acordo feito pelo grupo de estágio com os dois serviços envolvidos - CRAS e SEACOLHE-AIF (Seção de Acolhimento e Abrigo Provisório de Adultos, Idosos e Famílias em Situação de Rua) -, foram realizados acompanhamentos singulares de usuários em processo de saída do acolhimento para residência nos territórios de cobertura do CRAS-Centro, buscando identificar e contribuir para seu planejamento de saída do equipamento, fixação no território e vinculação com outros serviços, garantindo também seu direito de acompanhamento pelo CRAS.

O SEACOLHE-AIF é um serviço que realiza acolhimento institucional de média duração para pessoas e famílias em situação de rua e/ou em situação de perda de moradia. Fisicamente, fica nas proximidades do CRAS-Centro. A participação do estágio na interlocuçáo entre esses dois serviços teve como proposta estabelecer um fluxo entre a proteção social especial e a básica, a partir da saída dos usuários do serviço de acolhimento.

As estagiárias realizaram a tarefa de fazer acompanhamentos singulares de usuários que estavam no serviço de acolhimento com perspectivas de saída. Além disso, fizeram um mapeamento dos usuários do serviço de acolhimento que haviam saído nos últimos dois anos, identificando onde estavam residindo. O mapa mostrou algo que o próprio serviço parecia desconhecer: os locais da cidade para onde a maioria dos ex-moradores do serviço de acolhimento se deslocou, além da quantidade de usuários que retornaram para suas cidades de origem. Esse instrumento simples também contribuiu para dar materialidade e visualidade para o fato de que uma grande parte dos egressos do serviço (mais de $70 \%$ ), não havia recebido nenhum encaminhamento ou acompanhamento nem deixado registro ou informação de destino. Um outro achado que o mapeamento de egressos evidenciou foi que, dos que haviam registrado destino, a grande maioria (mais de $85 \%$ ) permanecia residindo no próprio território Centro. Alguns ainda frequentavam 
o serviço de acolhimento durante o dia, como local de convivência, como foi possível constatar posteriormente.

Assim, além de acompanhar uma pessoa em processo de saída do serviço de acolhimento, os estagiários fizeram o acompanhamento de dois egressos que residiam no próprio território Centro com objetivo de identificar e apoiar suas estratégias de vida no território, seu uso dos demais serviços e sua vinculaçáo com o CRAS. Assim, acompanhamos três usuários pensando o fluxo entre a proteção social especial (serviço de acolhimento) e a proteção social básica (CRAS) ao longo do período de estágio. Cada um dos acompanhamentos teve um percurso singular. A oportunidade de acompanhar o cotidiano de cada um deixou clara a sutileza que permeia as atitudes que podem determinar ou náo o ato de frequentar os serviços da assistência social.

Os acompanhamentos foram delineando a construção de um fluxo entre a proteção social especial (serviço de acolhimento) e a proteção social básica (CRAS), e cada um deles teve um percurso singular.

O primeiro acompanhamento ${ }^{2}$ foi de uma usuária que estava se desligando do serviço de acolhimento e havia acabado de ser inserida como beneficiária do Benefício de Prestação Continuada da Pessoa com Deficiência (BPC-PcD). Com o início do pagamento do benefício, ela recebeu auxílio da equipe do serviço e de seu irmão para localizar e alugar um quarto em um cortiço que fosse próximo ao Núcleo de Atenção Psicossocial (NAPS) que frequentava trimestralmente. A nova residência ficava próxima também do serviço de acolhimento. Foi acompanhada pelos estagiários no processo de adaptação e de organização da nova vida, tanto na estruturação da casa quanto na organização do cotidiano, assim como nas atividades de vida diária (como autocuidados e cuidados domésticos) e nas atividades instrumentais de vida prática (como ir ao supermercado, ao banco, aos serviços públicos). Coube aos estagiários acompanhá-la em sua inserção na rede de proteção social básica, apresentando-lhe o CRAS, além de outros equipamentos do território, como o centro de convivência. O exercício de ser terapeuta ocupacional dentro da assistência social contribuiu para a compreensão de como o usuário pode ser inserido nos serviços e incentivado a ampliar sua participaçáo social a partir do uso do território. $\mathrm{O}$ acompanhamento foi um desafio constante ao longo dos períodos de estágio. $\mathrm{O}$ fato de estar em processo de desligamento do serviço de acolhimento permitiu que os estagiários fizessem juntos essa trajetória, buscando compreender o que é a proteção básica para um usuário que acaba de sair de um serviço de acolhimento.

A saída do serviço de acolhimento exigia que fosse verificada e acionada sua rede de suporte social, além do exercício de pensar como seria sua inserção na proteção social básica. Embora estivesse morando em um quarto alugado por seu irmáo (seu tutor, responsável pela administração de seu BPC) e tivesse filhos, netos e um companheiro com quem vivia, seguia frequentando diariamente o serviço de acolhimento, o qual reconhecia como lugar de apoio, convivência e referência. Apesar de o serviço de acolhimento ser um lugar conhecido e de grande familiaridade para ela, ao longo desses encontros percebeu-se que as forças institucionais que a marcavam nesse local eram tão grandes que chegavam a impedir que seus acompanhamentos tivessem como objetivo projetá-la para outros serviços. Havia ali certa relação de codependência entre o serviço e seus usuários, comum às instituiçóes totais.

Os encontros iniciais foram dedicados a ouvi-la com o máximo de atenção e disponibilidade possível, na intenção de compreender sua trajetória de vida. Além disso, investiu-se em seu acompanhamento singular territorial, buscando conhecer a cidade a partir de sua perspectiva. Como teve experiência de viver nas ruas por muitos anos, sua desenvoltura ao andar pelo Centro da cidade era evidente. Foi também nessas caminhadas que identificou, pouco a pouco, muitas pessoas e locais conhecidos, ao mesmo tempo que era reconhecida por várias pessoas, tanto transeuntes como comerciantes formais e informais da região. À medida que aconteciam, essas atividades eram reportadas à equipe do CRAS, que entendeu a necessidade de indicar um técnico de referência para essa usuária, prevendo o momento de desvinculação da estagiária. Produziram juntas, usuária e estagiária, um porta-retratos, atividade que se caracterizou como processo de desvinculação e despedida. Ao terminarem, escolheu colocar no porta-retratos uma fotografia de seu companheiro.

O segundo acompanhamento foi de um usuário que já havia saído há um ano do serviço de acolhimento, mas seguia morando no território Centro, vivendo em um quarto individual em uma hospedaria, paga com o BPC que passou a receber recentemente devido à deficiência adquirida após sofrer um acidente vascular encefálico, que lhe causou um distúrbio da fala. Viveu muitos anos nas ruas de Santos. Apesar de ser receptivo, mudava de humor rapidamente: alguns dias não queria conversar; outros, contava muitas coisas de sua vida pessoal atual e passada por meio da pouca escrita, de desenhos e de gestos, com muita dificuldade. 
Seu histórico era pouco conhecido, mesmo pelos serviços onde já esteve. Por vezes, escrevia algumas palavras com dificuldade. Contou que estudou somente até a terceira série do ensino fundamental, que já foi casado, que teve muitos filhos, que já trabalhou como motorista e que sentia falta de dirigir. Em uma visita ao museu da pesca com outro grupo de estagiários, mostrou uma foto na qual estava presente, uniformizado como cadete da marinha. Aos poucos, recolhiam-se fragmentos de sua história. Identificou-se nesse usuário uma forte timidez - ou constrangimento - ao tentar comunicar-se com as pessoas devido às dificuldades que possuía. Ele confirmou essa suspeita, mostrando por meio de desenhos e sinais que náo ia ao restaurante social, pois não conseguia manipular talheres nem pedir a comida que desejava e normalmente as pessoas nâo o entendiam.

Diante disso, foi levantada a possibilidade de aprender a comunicar-se por meio da Linguagem Brasileira de Sinais (LIBRAS). Mostrou-se empolgado, aceitando prontamente a proposta. Foi feita com ele uma visita à biblioteca municipal para mostrar-lhe algo sobre o assunto e investir nessa forma de comunicação, fazendo articulaçóes com seu contexto de vida. Posteriormente, as estagiárias confeccionaram um quadro de comunicação alternativa e um pequeno papel com o alfabeto em libras. Ele se interessou pelo alfabeto principalmente. No encontro seguinte, já o havia decorado. Identificou-se nessa situação a relação direta entre a dificuldade de comunicação, potencializada pela ausência de repertório alternativo, e o empobrecimento das redes de sociabilidade do usuário, o que reduz suas possibilidades de participaçáo social e o uso da cidade. $\mathrm{O}$ alfabeto de libras náo se constituiu como instrumento comunicativo apenas, mas sim - e principalmente - como estratégia de ampliação do campo de visão para que pudesse saber da existência de outros meios possíveis e aumentar seu repertório. Funcionou, dessa forma, como mediador entre o sujeito e o mundo, apresentando-lhe a possibilidade de rever suas relaçóes sociais e modos de vida.

O terceiro acompanhamento foi de um usuário que nasceu na Bahia e residia em Santos há 30 anos. Saiu do serviço de acolhimento há um ano e morava em um quarto cujo locação era paga com o benefício que recebia, o BPC-Idoso. No início, o acompanhamento foi domiciliar, porém, com o tempo, foi negociado que os encontros ocorressem no CRAS. Esse foi um grande avanço, pois o usuário antes não entrava no CRAS de forma alguma, com receio de que pudessem abrigá-lo novamente. Os encontros nâo ocorriam com data marcada, pois muitas vezes ele passava por consultas médicas agendadas. Então, ele anotou os horários em que os estagiários estariam disponíveis no CRAS e ia espontaneamente - muitas vezes chegava mais cedo e aguardava, na entrada, a chegada dos estagiários.

Em seu histórico, constatamos que ele trabalhou como estivador de café. Com o tempo, estabeleceu-se como músico de casas noturnas. Teve problemas com a justiça, passando dois anos na prisão. Quando saiu, sem seus documentos, passou a dormir nas ruas. Tempos depois, resolveu procurar o "plantão social", serviço que funcionava como porta de entrada da proteção social de pessoas em situação de rua, antes do reordenamento dos serviços do SUAS. Tirou novamente seus documentos e voltou a fazer tratamento para um antigo problema na coluna. Recebeu de seu médico a notícia de que estava incapacitado para o trabalho, mas náo conseguiu com isso receber o $\mathrm{BPC}-\mathrm{PcD}$, tendo que atingir a idade para poder receber o BPC-Idoso.

Desde que começou a receber o benefício, vinha encontrando problemas em administrá-lo, o que o levou a contrair dívidas com lojas, com amigos e no cortiço onde residia. Não conseguia tocar violáo nem cantar como antes devido às dores. Ainda assim, tinha intenção de gravar um CD Demo para divulgar seu trabalho como músico. Foi levantada a possibilidade da realização da gravação gratuita de um CD com cinco músicas por um estúdio em São Paulo. Como possuía dificuldades em administrar o benefício que recebia, foi traçado um plano com ele, no qual deveria economizar para poder pagar a passagem e a alimentação em sua ida a São Paulo. Logo nas primeiras semanas já havia economizado o suficiente, mas suas dores e limitaçóes físicas pareciam aumentar a cada dia. As estagiárias o incentivaram e o encaminharam para retomar o tratamento médico. Foi diagnosticado o início da doença de Parkinson, além de uma catarata em estágio avançado. O usuário, então, considerou que a gravação do CD náo era uma prioridade, pois ponderou que passar o dia inteiro em São Paulo seria muito cansativo e diminuiria ainda mais sua condição física para cantar e tocar - a identificação da doença indicava que não poderia trabalhar como músico, como desejava. Tendo desenvolvido estratégias de economia e administração de sua renda, usou o dinheiro economizado para quitar parte de suas dívidas. Uma parte importante do processo de organizaçáo financeira é a tomada de decisão acerca do emprego dos valores economizados, e a decisão desse usuário de quitar suas dívidas e dedicar-se ao tratamento médico, além de - por sua decisão - estreitar seu vínculo com o CRAS por meio do destacamento de 
um técnico de referência, apontou para a produção de autonomia, necessária e desejada.

A maneira como esses acompanhamentos foram realizados permitiu que entrássemos em profundo contato afetivo com as pessoas, compreendendo um pouco mais a respeito dos lugares por onde transitavam, como constituíam seu cotidiano, o que gostavam de fazer e suas necessidades.

O trabalho de levar essas peculiaridades até a equipe foi praticamente artesanal, e todos os acontecimentos, no que diz respeito aos fluxos, pareciam ser inéditos para a equipe que acompanhava os usuários. Houve esforço diário da nossa equipe em fazer com que os técnicos dos serviços envolvidos pudessem discutir formas para que os cadastros fossem realizados com efetividade em ambos os serviços e pudessem ser pesquisados, reforçando essa rede de suporte (SAVIANI et al., 2014).

Tivemos como tarefa a criação de alicerces possíveis para esse tipo de ação, acreditando que os investimentos de quem acompanha esses usuários devem apoiar-se na importância de que, em alguns casos, deve haver um acompanhamento mais cuidadoso nesse trânsito entre equipamentos da assistência social (SAVIANI et al., 2014). A esse processo de acompanhamento "parelhado", no qual vamos "junto", é preciso olhar com destaque, pois facilmente se confunde com ação assistencialista. Mas o que estamos falando, de fato, é de um encaminhamento acompanhado, apoiado. Estamos falando da prática de acompanhamento em território, ação comum ao terapeuta ocupacional: ir junto à escola, ao serviço de saúde, ao CRAS, ao INSS, com objetivo de emprestar contratualidade e apostar na autonomia construída em processo, e não prescrita como recurso apriorístico do usuário.

Esse processo permitiu que se enxergasse o grande abismo existente entre os serviços da proteção social especial e os da proteção social básica, o que nos levou a reflexôes e buscas para construção de fluxos e pontes entre os níveis de proteçấo social. Os três usuários acompanhados demonstraram a condição de alta vulnerabilidade que se colocaram após o desligamento do serviço de acolhimento, o que os levaria em breve de volta ao mesmo serviço do qual haviam saído. Assim, definiu-se por reunióes periódicas entre os dois serviços envolvidos, buscando garantir o vínculo com o CRAS desde antes da saída do acolhimento, de forma que, ao saírem, já tivessem seu registro no Cadastro Único (CadÚnico), e suas condições de apoio financeiro avaliadas e encaminhadas (como inserção em programas de bolsas, benefícios, geração de renda ou emprego apoiado). Além disso, evidenciou-se a necessidade de acompanhar os usuários egressos do serviço de acolhimento em suas demandas, o que significa conhecê-los e apoiá-los nas perspectivas de inserção e uso dos territórios da cidade. Os usuários aqui acompanhados foram aqueles indicados pelo serviço de acolhimento, pois eram considerados situaçóes levadas a termo, ou seja, com desligamento previsto e acompanhado até a saída do serviço. Entretanto, as reunióes entre serviços permitiram, entre outras coisas, questionar essa concepção, na qual o usuário, por passar a ter uma fonte de renda - bolsa, benefício, emprego ou outra - passa a ser automaticamente considerado "desligado", e o serviço, portanto, desresponsabilizado.

\subsection{Composição de trabalho CRAS e Serviço de Convivência para Jovens}

Os Serviços de Convivência para Jovens são instituições voltadas para o público juvenil e têm como objetivo propor açóes culturais, educacionais e sociais. Na cidade de Santos, de onde parte esta experiência, eles são conhecidos pela sigla CEJUV, que significa Centro da Juventude. Esses espaços sempre integraram a Secretaria Municipal de Assistência Social da referida cidade e foram inaugurados na década de 1990, ou seja, mais de 10 anos antes da estruturação do SUAS. Com a implantação e ordenamento do SUAS, os CEJUVs, que eram unidades autônomas, passaram a compor a rede da assistência social na condição de "Serviços de Convivência e Fortalecimento de Vínculos". Assim, passaram a responder diretamente aos CRAS. Isso causou duas mudanças significativas na organização do trabalho: 1 . atender "somente" aos jovens provenientes de famílias beneficiárias de programas sociais; 2 . prestar contas de suas açóes à coordenação do CRAS.

Nos primeiros anos de implantaçáo do SUAS, esse referenciamento e suas consequências ficaram menos explícitas, pois os CRAS tinham outras muitas - funções para serem viabilizadas, entre elas compreender a complexidade do seu território, além de todo trabalho técnico-burocrático em que a assistência social está imersa. Com o passar do tempo, e com nossa inserção via estágio tanto no CRAS quanto no CEJUV do território Centro ${ }^{3}$, os técnicos de ambas as instituiçóes reconheciam a necessidade de se aproximarem, compreenderem mutuamente seus processos de trabalho e suplantarem a lógica reinante do encaminhamento. Para isso, solicitaram nossa ajuda e passamos a compor estratégias para responder a essas "novas demandas". 
Por dentro do CRAS, iniciamos um movimento de explicitar as necessidades advindas dos adolescentes e jovens, que ficavam subsumidos nas dinâmicas familiares que chegavam para os técnicos do CRAS. Assim, com um dos técnicos, o mais disponível em lidar com as questôes pertinentes à juventude, passamos a listar, via o CadÚnico, os jovens que poderiam beneficiar-se das atividades propostas no CEJUV e, em um segundo momento, passamos a realizar visitas domiciliares para conhecê-los, seus interesses e dificuldades. Com alguns desses jovens, em vez de fazermos encaminhamentos verbais ou escritos, oferecemo-nos para irmos com eles ao CEJUV - uma aposta na potência do encaminhamento acompanhado -, entendendo que isso favoreceria sua futura inserção naquele espaço. A experiência demonstrou que, de fato, essa estratégia de "encaminhamento acompanhado" é mais assertiva do que indicar, pelo discurso, a importância da realização de atividades.

Também foi assertivo sugerirmos a participação do técnico do CRAS em algumas atividades do CEJUV, pois passou a ser mais factível para eles compreenderem o que era realizado. Pretendia-se com isso que o CRAS deixasse o lugar de fiscalização das ações do CEJUV, colocando-se como apoiador, incentivador e colaborador dessas açôes. Conhecendo de fato o CEJUV, os técnicos do CRAS, ao fazerem atendimento a famílias que possuíam filhos adolescentes/jovens, tinham mais elementos para explicar o que o CEJUV oferecia. Com o tempo, foi tornando-se mais claro que, ao se dizer sobre as ofertas de atividades no CEJUV, falava-se sobre o que o CRAS ofertava, na medida em que se compreendia o CEJUV como parte do trabalho do CRAS.

No CEJUV, realizamos também encontros com os educadores, com objetivo de esclarecer sobre o novo desenho da PNAS e o novo fluxo entre CRAS-CEJUV. Os trabalhadores tinham a sensação de uma certa imposição de instâncias acima deles para a existência desse novo fluxo. Com as compreensóes ampliadas, diminuíram-se as resistências, e esses trabalhadores passaram a compreender e a atender ao recorte societário de juventude apontado pela PNAS, além de perceberem a viabilidade de um trabalho conjunto com o CRAS.

Os técnicos do CRAS tinham um conhecimento com as famílias que os trabalhadores do CEJUV não possuíam por falta de tempo e de formação. Com o passar dos meses, evidenciou-se que, nessa composição, todos saíam ganhando, em especial os jovens.
Na perspectiva da Terapia Ocupacional Social, também desenvolvíamos um trabalho com jovens voltado para o fortalecimento de vínculos familiares e comunitários, destacando-se: a condução de oficinas que visavam à transformação estética dos espaços físicos; apoio às oficinas "Vivências Juvenis", que trabalhavam com temas transversais e atuais da juventude demandados pelos próprios jovens e/ou respondendo a questóes advindas do próprio contexto nos quais eles estavam inseridos (apoio tanto no planejamento como na execução das atividades, com vistas a qualificá-las, por meio da invençáo de recursos que aglutinassem mais os jovens, e do aprofundamento do debate político e social das açôes); a produção de um documentário no qual os jovens explicitaram sua percepção sobre esse espaço; realização de acompanhamentos singulares (nos casos que traziam demandas mais complexas, como situaçóes de violência e de negligência, a participação do técnico do CRAS era fundamental para dar-nos o suporte necessário para enfrentarmos as problemáticas em tela).

Tivemos a oportunidade de desenhar, em diálogo constante com ambas as equipes, um modelo demonstrativo de um trabalho conjunto entre serviços. Esse desenho certamente ganhará outros contornos, cores e formas na medida em que novos atores se incluam. Há de se ressaltar que é um trabalho (in) tenso, pois as instituiçôes, de um modo geral, são extremamente endógenas, ou seja, tendem a se fechar nelas mesmas. Ao propor o trabalho institucional em diálogo com o de "fora", com o "externo" - ou seja, ao se sustentar radicalmente a construção de fluxos e de relaçóes de sistema, como proposto na PNAS -, constata-se sua complexidade, por isso é um exercício que deve ser constante no trabalho cotidiano do técnico de qualquer formação. Isso não é fácil de ser feito.

Arriscamos inferir que a Terapia Ocupacional vem, ao longo de sua história, acumulando conhecimento sobre esse trânsito de dentro para fora das instituiçóes e entre elas, investindo esforços para dentro da vida cotidiana das pessoas e, portanto, para todos os locais e deslocamentos possíveis, o que lhe confere, hoje, certa facilidade e autonomia na realização de tais açóes.

Apesar de complexo, é um trabalho factível. $\mathrm{Na}$ composição, a possibilidade de haver uma somatória é grande, desde que haja disponibilidade para ela. E somar, no campo social no trabalho com jovens, pode ser traduzido em ampliar projetos de futuro, ampliar direitos sociais. 


\section{Conclusão}

Esse desenho de estágio tem explicitado o desafio de formar o terapeuta ocupacional com base na demanda do outro, fundamentado na perspectiva do território e da intersetorialidade enquanto campo e prática de resolutividade. Algo simples de ser falado, mas difícil de ser realizado. Ainda temos uma formação hegemônica na Terapia Ocupacional, centrada na valorizaçáo da técnica como um dado a priori, definido antes de se conhecer o outro para quem - e com quem - deveria ser pensada e colocada à disposição.

Além disso, desafiamo-nos a formar profissionais em uma especialidade que exige um repertório teórico do campo de conhecimento das Ciências Humanas e Sociais, dentro de - e em enfrentamento com - uma proposta curricular que privilegia a formação nas Ciências Biológicas e da Saúde. Esse perfil de formação não se restringe à UNIFESP ${ }^{4}$. Como bem demonstrou Pan (2014), essa desproporcionalidade é comum a muitos outros projetos políticos pedagógicos de cursos de Terapia Ocupacional das universidades públicas brasileiras. Para essa autora, enquanto retórica da categoria profissional, reproduzimos discursivamente a máxima de que queremos superar o modelo biomédico hegemônico. Contudo, continuamos, na prática da formação profissional, destinando boa parte da carga horária dos currículos para esse tipo de conteúdo (PAN, 2014).

Outra questão que, enquanto profissão e formação, não conseguimos resolver é sobre como formar os estudantes em novos campos de estágio sem a figura do preceptor local. Na experiência relatada, a universidade cedeu parte da carga horária das professoras para estar nos serviços. Porém, diante das demandas colocadas para a carreira do professor universitário, estar 12 horas no serviço para acompanhar de quatro a seis estudantes é insustentável. Nesse cenário, havíamos pactuado com a gestão municipal de que, após dois anos de estágio, seria feita avaliação e, em caso positivo, seriam abertas negociações para contratação de terapeutas ocupacionais para a assistência social. Esse processo resultou na menção ao estágio de Terapia Ocupacional como sendo a principal inovaçáo dessa Secretaria, no relatório ao Ministério de Desenvolvimento Social de 2013, na criação do cargo de terapeuta ocupacional na assistência social e na abertura da primeira vaga para terapeuta ocupacional na assistência social da cidade.

Consideramos que as negociaçóes locais para a contrataçáo de terapeutas ocupacionais são as melhores alternativas para abrirmos campos profissionais e de estágio. Contudo, há ainda muita disputa entre as categorias profissionais que se sentem, de certa forma, ameaçadas com a possibilidade da perda de seus nichos tradicionais de trabalho.

Assim, faz-se necessário construir pontes de diálogo com os diferentes profissionais, compreender e negociar com seus tempos, disponibilidades e responsabilizaçóes, auxiliar e estimular o estudante a realizar muitos deslocamentos - geográficos (longos trajetos entre os equipamentos), subjetivos (entre diferentes valores morais/culturais que se explicitam e não devem ser julgados) e teóricos (apropriação de novos repertórios teóricos, reconstrução e questionamento dos seus referenciais) - e problematizar a história e os modos de constituição da rede de assistência social construída na lógica anterior à PNAS, ainda pautada no assistencialismo, que possui poucos equipamentos públicos e conta com uma estrutura humana incipiente diante da diversidade $\mathrm{e}$ complexidade da demanda social da região Centro.

\section{Referências}

BARROS, D. D.; GHIRARDI, M. I. G.; LOPES, R. E. Terapia ocupacional e sociedade. Revista de Terapia Ocupacional da Universidade de São Paulo, São Paulo, v. 10, n. 2-3, p. 69-74, 1999.

BARROS, D. D.; GHIRARDI, M. I. G.; LOPES, R. E. Terapia Ocupacional Social. Revista de Terapia Ocupacional da Universidade de São Paulo, São Paulo, v. 13, n. 2, p. 95-103, 2002.

BARROS, D. D.; LOPES, R. E.; GALHEIGO, S. M. Terapia Ocupacional Social: concepçôes e perspectivas. In: CAVAlCANTI, A.; GALVÃO, C. (Org.). Terapia Ocupacional: fundamentação e prática. Rio de Janeiro: Guanabara Koogan, 2007. p. 347-353.

BRASIL. Ministério do Desenvolvimento Social e Combate à Fome. Politica Nacional de Assistência Social (PNAS-2004). Brasília, 2004. Disponível em: <http:// www.mds.gov.br/assistenciasocial/suas>. Acesso em: 10 abr. 2011.

BRASIL. Ministério do Desenvolvimento Social e Combate à Fome. Norma Operacional Básica NOB/SUAS. Brasília: Secretaria Nacional de Assistência Social, 2005.

BRASIL. Ministério do Desenvolvimento Social e Combate à Fome. Conselho Nacional de Assistência Social. Resoluçáo no 172, de 20 de setembro de 2007. Recomenda a instituição de Mesa de Negociação na forma estabelecida na Norma Operacional de Recursos Humanos do Sistema Único de Assistência Social/ NOB-RH/ SUAS. Diário Oficial da República Federativa do Brasil, Brasília, DF, 4 out. 2007. Seção1. Disponível em: <http://www.mds.gov.br/cnas/legislacao/legislacao/resolucoes/legislacao/resolucoes>. Acesso em: 10 abr. 2011.

CASTEL, R. Da indigência à exclusão, a desfiliação: precariedade do trabalho e vulnerabilidade relacional. 
In: LANCETTI, A. Saúde Loucura. São Paulo: Hucitec, 1994. p. 21-48.

INSTITUTO BRASILEIRO DE GEOGRAFIA E ESTATÍSTICA - IBGE. Cidades@: Santos. Disponível em: <http://cidades.ibge.gov.br/xtras/perfil. php? codmun=354850>. Acesso em: 20 jan. 2017.

JUNQUEIRA, L. A. P. Intersetorialidade, transetorialidade e redes sociais na saúde. Revista de Administração Pública, Rio de Janeiro, v. 34, n. 6, p. 35-45, 2000.

LOPES, R. E. et al. Expressão livre de jovens por meio do Fanzine: recurso para a terapia ocupacional social. Saúde e Sociedade, São Paulo, v. 22, n. 3, p. 937-948, 2013.

OLIVER, F. C.; BARROS, D. D. Reflexionando sobre deinstitucionalización y terapia ocupacional. Matéria prima - primeira. Materia - Prima, Primera Revista Independiente de Terapia Ocupacional, Argentina, v. 4, n. 13, p. 17-20, 1999.

PAN, L. C. Politicas de Ensino Superior, Graduação em Terapia Ocupacional e o Ensino de Terapia Ocupacional Social no Brasil. 2014. 224 f. Dissertação (Mestrado em Terapia Ocupacional) - Universidade Federal de São Carlos, São Carlos, 2014.

SAVIANI, A. C. et al. O acompanhamento territorial como estratégia de cuidado na Assistência Social: uma experiência transeunte. Revista Saúde na Comunidade, São Paulo, v. 1, n. 5, p. 44-44, 2014.

TATAGIBA, L. Conselhos gestores de políticas públicas e democracia participativa: aprofundando o debate. Revista Sociologia Politica, Curitiba, v. 25, n. 25, p. 209 213, 2005.

\section{Contribuição dos Autores}

Patrícia e Samira são responsáveis pela concepção do texto e organização dos dados. Todas as autoras trabalharam na redação e aprovaram a versão final do texto.

\section{Notas}

${ }^{1}$ Referimo-nos à Resolução no 17, de junho de 2011, do Conselho Nacional da Assistência Social, que ratifica a equipe de referência definida pela Norma Operacional Básica de Recursos Humanos (NOB-RH) do Sistema Único de Assistência Social (SUAS) (BRASIL, 2007) e reconhece categorias profissionais de nível superior, entre elas a Terapia Ocupacional, para atender às especificidades dos serviços socioassistenciais e das funçôes essenciais de gestão do SUAS.

${ }^{2} \mathrm{O}$ relato desse acompanhamento singular pode ser acessado em Saviani et al. (2014).

${ }^{3}$ A inserção no Centro da Juventude se dava também por meio de atividade extensionista do Núcleo METUIA da UNIFESP.

${ }^{4}$ Nos últimos três anos, o corpo docente vem se debruçando sobre o Projeto Político Pedagógico e acumulando crítica em relação à desproporcionalidade dos conteúdos mencionada. A nova proposta entrou em vigor em 2016. 